\title{
DEVELOPMENT AND VALIDATION OF HPTLC DENSITOMETRY METHOD FOR SIMULTANEOUS ESTIMATION OF ROSIGLITAZONE AND GLIMEPIRIDE IN FIXED TABLET DOSAGE FORM
}

\author{
SEEMA M. DHOLE ${ }^{*}$, PRAMOD B. KHEDEKAR ${ }^{2}$, NIKHIL D. AMNERKAR ${ }^{l}$ \\ ${ }^{I}$ Department of Pharmaceutical Chemistry, Sharad Pawar College of Pharmacy, Rashtrasant Tukadoji Maharaj Nagpur \\ University, Nagpur-441110, M.S., India. \\ ${ }^{2}$ University Department of Pharmaceutical Sciences, Rashtrasant Tukadoji Maharaj Nagpur University, Nagpur-440033, M.S., India.
} (Received: February 29, 2012 - Accepted: March 21, 2013)

\begin{abstract}
A new, simple, precise, and accurate high performance thin layer chromatography (HPTLC) densitometry method has been developed for simultaneous estimation of rosiglitazone maleate (ROSI) and glimepiride (GLIM) in tablet dosage form. Procedure does not require prior separation of components from the sample. Chromatographic separation of the drugs was performed on aluminum plates precoated with silica gel $60 \mathrm{~F}_{254}$ as the stationary phase and the solvent system consisted of methanol: toluene: ethyl acetate $(1: 8: 1, \mathrm{v} / \mathrm{v} / \mathrm{v})$. Densitometric evaluation of the separated zones was performed at $228 \mathrm{~nm}$. The drugs were satisfactorily resolved with $\mathrm{R}_{\mathrm{f}}$ values $0.39 \pm 0.03$ and $0.20 \pm 0.04$ for ROSI and GLIM, respectively. Parameters such as linearity, precision, accuracy, recovery, specificity, and ruggedness were studied as reported in the International Conference on Harmonization (ICH) guidelines. The linearity regression analysis for calibration showed correlation coefficients $\mathrm{R}^{2}$ valve 0.9989 and 0.9996 for ROSI and GLIM, respectively with respect to peak area in the concentration range of $100-1500 \mathrm{ng} / \mathrm{spot}$. The mean percentage recovery values were close to $100 \%$, it indicates that there is no interferences of additives with ROSI and GLIM present in tablet dosage form. Statistical analysis proved that the method is suitable for the quality control analysis of ROSI and GLIM as a bulk drug and in pharmaceutical formulations. The study may be extended to comprehend the degradation kinetics of these two drugs.
\end{abstract}

Keywords: Rosiglitazone maleate, Glimepiride, HPTLC, Densitometry, Validation.

\section{INTRODUCTION}

Type 2 diabetes is a long term metabolic disorder wherein the body becomes resistant to the effects of insulin, a hormone that regulates sugar absorption. Treatment of type- 2 diabetes (non insulin dependent) is now possible with orally administered hypoglycemic agents that help to reduce blood sugar levels. ${ }^{1}$ To control this disorder, combination therapy is often used. Rosiglitazone maleate (ROSI) and Glimepiride (GLIM) are widely used to treat type-2 diabetes. Rosiglitazone, chemically $[( \pm)-5-[4-[2-[N$-methyl- $N(2-$ pyridyl)amino]-ethoxy]benzyl]-2,4-dione thia- zolidine] (Fig. 1), is a potent oral antihyperglycemic agent that reduces insulin resistance in patients with type-2 diabetes by binding to peroxisomal proliferator-activated receptors gamma (PPAR- $\gamma)^{2,3}$<smiles>CN(CCOc1ccc(CC2SC(=O)NC2=O)cc1)c1ccccn1</smiles>

Fig. 1. Chemical structure of ROSI

Few capillary electrophoresis ${ }^{4}$, LC/MS HPLC in human plasma ${ }^{5}$, LC in pharmaceutical formulation and human plasma ${ }^{6,7}$, MEKC and HPLC $^{8}$, solid phase extraction coupled with LC- MS/MS ${ }^{9}$, HPTLC ${ }^{10}$ methods have been reported for analytical monitoring of ROSI individually and with other drugs.

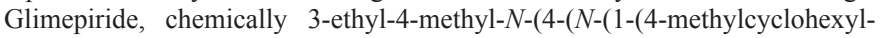
amino)vinyl)-sulfamoyl)phenethyl)-2-oxo-2,5-dihydro- $1 H$-pyrrole- 1 carboxamide, is a sulphonyl-urea antidiabetic drug and its structure is shown in Fig. $2 .{ }^{11}$

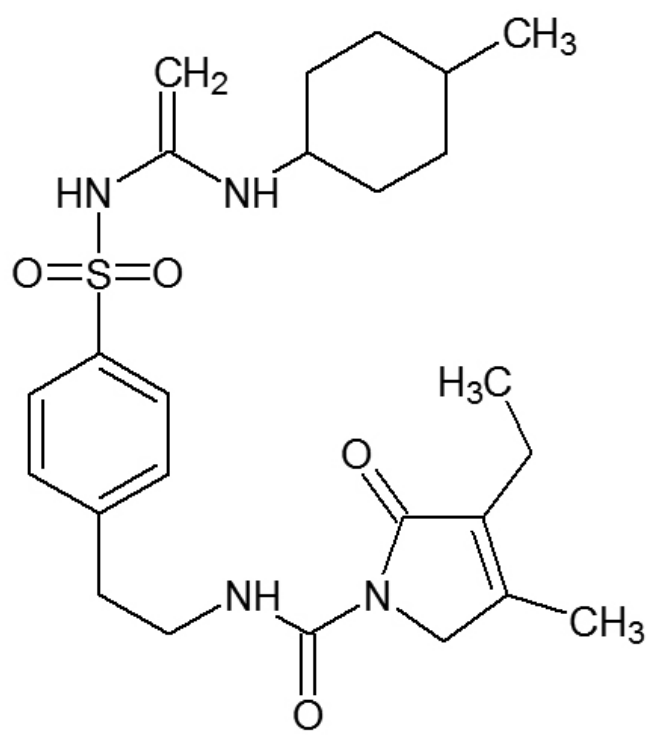

Fig. 2. Chemical structure of GLIM

Literature survey revealed that derivative spectrophotometric ${ }^{12}, \mathrm{HPLC}^{13}$ and HPLC-ESI-MS-MS ${ }^{14}$, HPTLC ${ }^{15,16}$ methods are available for GLIM estimation alone and with other drugs. Today TLC is rapidly becoming a routine analytical technique due to its advantages of low operating costs, high sample throughput and the need for minimum sample preparation. The major advantage of TLC is that several samples can be run simultaneously using a small quantity of mobile phase unlike HPLC thus reducing the analysis time and cost per analysis. Till date, to the best of our knowledge, no HPTLC method has been reported in the literature for estimation of ROSI and GLIM in combined dosage form.

In the present work, an attempt has been made to develop simple, precise, accurate HPTLC method for simultaneous estimation of ROSI and GLIM in tablet dosage form. The proposed method is validated as per ICH guidelines. ${ }^{17}$

\section{EXPERIMENTAL}

Chemicals and Reagents

Pharmaceutically pure sample of ROSI and GLIM were obtained as generous gifts from Panacea Biotec Ltd., Malpur, Solan (H.P.), India and Medley Pharmaceuticals Ltd., Bari Brahmana, Jammu, India, respectively. 
A combination of ROSI $(2.0 \mathrm{mg})$ and GLIM $(1.0 \mathrm{mg})$ in tablet formulation (Rosicon-G, Glenmark Pharmaceuticals Ltd., Baddi, H.P., India) was obtained from local market commercially. All the chemicals used were of analytical grade, obtained from E.Merck, Mumbai, India.

\section{Instrumentation}

The samples were spotted in the form of bands of width $6 \mathrm{~mm}$ with a Camag 100 microlitre sample syringe (Hamilton, Switzerland) on aluminium plates precoated with silica gel $60 \mathrm{~F}_{254}[10 \mathrm{~cm} \mathrm{X} 10 \mathrm{~cm}$ with $250 \mu \mathrm{m}$ thickness; E. Merck, Darmstadt, Germany] using a Camag Linomat V (Switzerland) sample applicator. The plates were prewashed with methanol and activated at $110^{\circ} \mathrm{C}$ for $5 \mathrm{~min}$ prior to chromatography. A constant application rate of $0.1 \mu \mathrm{l} / \mathrm{s}$ was used. The space between two bands was $5 \mathrm{~mm}$ and 6 tracks were applied per plate. The slit dimension was kept at $5 \mathrm{~mm} \mathrm{X} 0.45 \mathrm{~mm}$ and the scanning speed was $10 \mathrm{~mm} / \mathrm{s}$.

The mobile phase consisted of methanol: toluene: ethyl acetate in the proportion of $1: 8: 1, \mathrm{v} / \mathrm{v} / \mathrm{v}$ and $10 \mathrm{ml}$ of mobile phase was used per chromatography run. Linear ascending development was carried out in a $20 \mathrm{~cm}$ X $10 \mathrm{~cm}$ twin rough glass chamber (Camag, Muttenz, Switzerland) saturated with the mobile phase. The optimized chamber saturation time for the mobile phase was $30 \mathrm{~min}$ at room temperature $\left(25^{\circ} \mathrm{C} \pm 2\right)$ at relative humidity of $60 \% \pm 5$. Each chromatogram was developed over a distance of $8 \mathrm{~cm}$

After the development the TLC plates were dried in a stream of air with the help of an air dryer in a wooden chamber with adequate ventilation. Densitometric scanning was performed using a Camag TLC Scanner III in the reflectance absorbance mode at $228 \mathrm{~nm}$ and operated by WinCATS software. The source of radiation used was deuterium lamp emitting a continuous UV spectrum between 200 and $400 \mathrm{~nm}$. Concentrations of the compound chromatographed were determined from the intensity of the diffused light Evaluation was performed by linear regression of peak areas determined by UV absorption as a function of sample amounts.

\section{Preparation of standard solutions}

Standard stock solutions of each concentration $1000 \mu \mathrm{g} / \mathrm{ml}$ of ROSI and GLIM were prepared separately using methanol. From the standard stock solution, the diluted mixed standard solution was prepared using the methanol to contain $200 \mu \mathrm{g} / \mathrm{ml}$ of ROSI and $100 \mu \mathrm{g} / \mathrm{ml}$ of GLIM, respectively.

\section{Optimization of the HPTLC method}

The TLC procedure was optimized with a view to develop a simultaneous assay method for ROSI and GLIM, respectively. The mixed standard stock solution $(200 \mu \mathrm{g} / \mathrm{mL}$ of ROSI and $100 \mu \mathrm{g} / \mathrm{mL}$ of GLIM) was taken and $6 \mu \mathrm{l}$ sample was spotted on to TLC plates and run in different solvent systems. After trying several permutation and combination, finally the mobile phase consisting of methanol: toluene: ethyl acetate in the proportion of 1:8:1 v/v/v was found optimum as it gave well separated band of the drugs, as compared to other mobile phases (Fig. 3).

In order to reduce the neckless effect, TLC chamber was saturated for 30 min using saturation pads. The mobile phase was run up to a distance of $8 \mathrm{~cm}$; which takes approximately 15-20 min for complete development of the TLC plate.

After application and development of bands of the working standard solution, the separated bands on the HPTLC plate were scanned over the wavelength range $200-400 \mathrm{~nm}$. The wavelength selected for densitometric determination was $228 \mathrm{~nm}$. The spectrums obtained are depicted in Fig. 4 and Fig. 5.

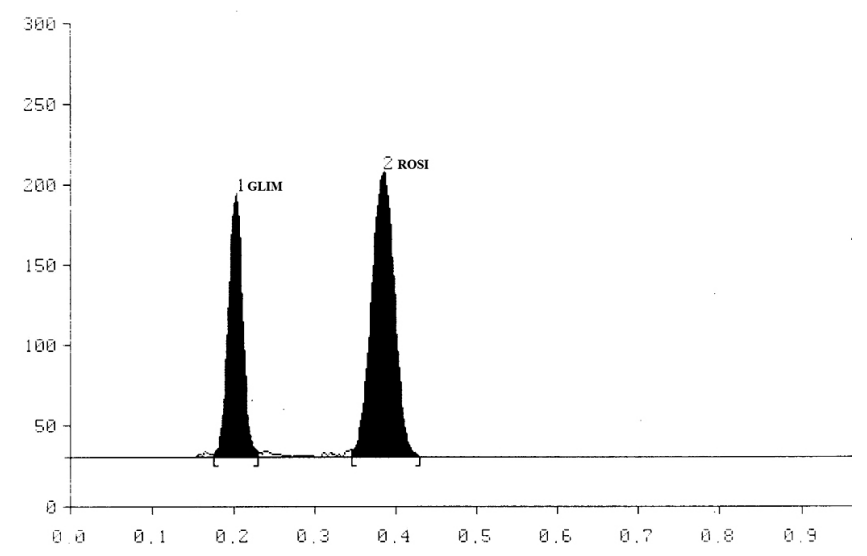

Fig. 3. Chromatogram of standard solution of ROSI and GLIM.

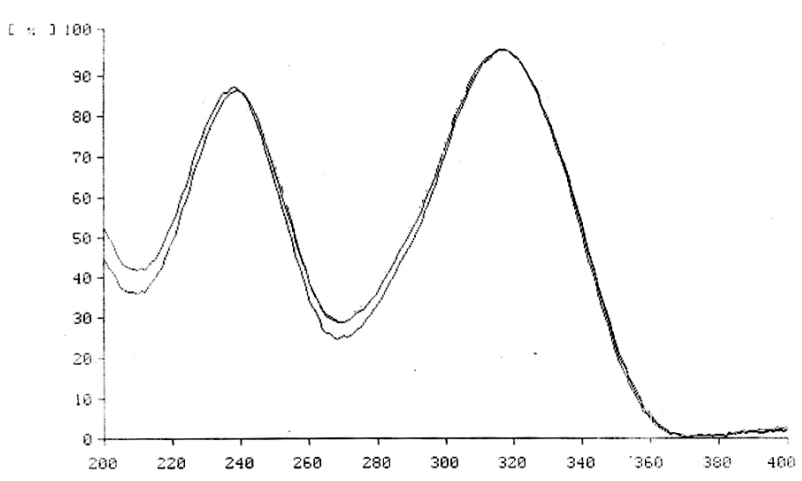

Fig. 4. Spectrum of ROSI $(200-400 \mathrm{~nm})$.

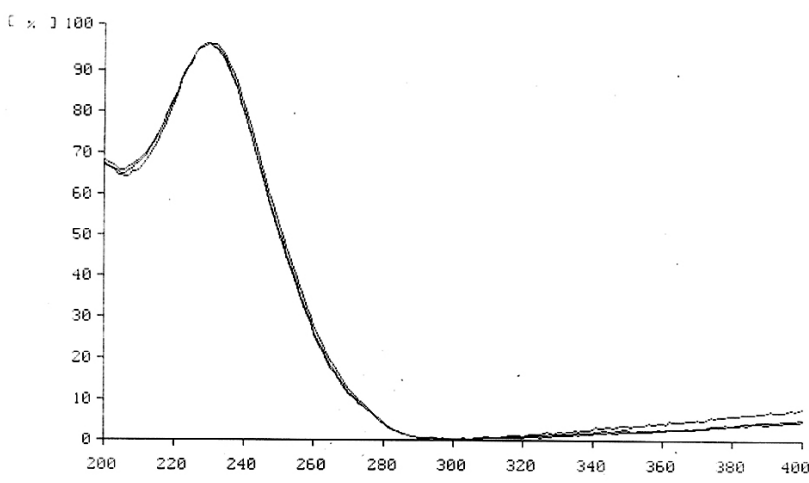

Fig. 5. Spectrum of GLIM (200-400 nm).

\section{Analysis of tablet formulation}

Twenty tablets were weighed and average weight was calculated. The tablets were triturated to a fine powder. An accurately weighed quantity of powder equivalent to $10 \mathrm{mg}$ of ROSI was transferred to $10 \mathrm{ml}$ volumetric flask and dissolved in $5 \mathrm{ml}$ of methanol, sonicate for $15 \mathrm{~min}$ with occasional shaking and volume was adjusted up to $10 \mathrm{ml}$ with same solvent. The solution was filtered through Whatman filter paper No.42 and aliquot portion of the above filtrate was diluted to obtain a solution of $200 \mu \mathrm{g} / \mathrm{ml}$ and $100 \mu \mathrm{g} / \mathrm{ml}$ of ROSI and GLIM, respectively. From the above sample solution $6 \mu \mathrm{l}$ was applied on prewash TLC plate with standard solution which gave final concentration of $1200 \mathrm{ng} / \mathrm{spot}$ for ROSI and $600 \mathrm{ng} / \mathrm{spot}$ for GLIM, which was developed and scanned in optimized conditions. The amount of ROSI and GLIM present per tablet was calculated by comparing peak area of sample with that of standard.

\section{Method validation}

Validation of the optimized TLC method was carried out with respect to the following parameters.

Linearity

From the diluted standard stock solution $100 \mu \mathrm{g} / \mathrm{ml}$ of each drug, 1 to 15 $\mu 1$ solution spotted on TLC plate to obtain final concentration 100 to $1500 \mathrm{ng} /$ spot for ROSI and 100 to $1500 \mathrm{ng} / \mathrm{spot}$ for GLIM. Linearity of the method was studied by applying six concentrations of the drug $(n=6)$ and each concentration was applied three times to the TLC plates. The plate was then developed using the previously described mobile phase and the peak areas were plotted against the corresponding concentrations to obtain the calibration curves.

Accuracy

The accuracy of the method was determined by calculating recoveries of ROSI and GLIM using standard addition method at different levels to the preanalyzed sample. For that known amounts of standard solutions of ROSI and $\operatorname{GLIM}(80,100$, and $120 \%$ of test concentration) were added to prequantified sample of tablet dosage form and determining their contents.

Precision

The precision of the method was verified by repeatability precision studies. Repeatability studies were performed by analysis the sample solutions of the drugs six times on the same day. Series of diluted standard solutions were prepared and analyzed by proposed method. 
Limit of detection and limit of quantitation

The limit of detection (LOD) and limit of quantitaton (LOQ) were separately determined based on standard deviation of the y-intercept and the slope of the calibration curve by using the equations (1) and (2), respectively.

$$
\mathrm{LOD}=\frac{3.3 \delta}{\mathrm{S}} \quad \mathrm{LOQ}=\frac{10 \delta}{\mathrm{S}}
$$

where, $\delta$ : standard of y-intercept and S: slope of calibration curve.

Ruggedness

Ruggedness of the proposed method was determined by analysis of sample solution prepared by proposed method between different time intervals, days, and analysts.

Specificity

The specificity of the method was determined by analyzing standard drug and test samples. The spots for ROSI and GLM in the samples were confirmed by comparing the $\mathrm{R}_{\mathrm{f}}$ and spectrum to the spots with that of a standards. The peak purity of ROSI and GLIM was determined by comparing at three different regions of the spot i.e. peak start (S), peak apex (M) and peak end (E).

\section{RESULTS AND DISCUSSION}

Literature survey reveals that no HPTLC method has been reported for simultaneous determination of ROSI and GLIM in combined tablet dosage form. So, the proposed HPTLC method was optimized with several solvent systems. The mobile phase consisting of methanol: toluene: ethyl acetate $(1: 8: 1, \mathrm{v} / \mathrm{v} / \mathrm{v})$ and aluminium plate precoated with silica gel $60 \mathrm{~F}_{254},(10 \mathrm{~cm}$ $\times 10 \mathrm{~cm}$ ) as stationary phase were used which gave good resolution with $\mathrm{R}_{\mathrm{r}}$ values of 0.39 and 0.20 for ROSI and GLIM, respectively. The well defined peaks were obtained only when the chamber was saturated with the mobile phase for $30 \mathrm{~min}$ at a controlled temperature before plate development and UV detection was carried out at $228 \mathrm{~nm}$. Resolution of the peaks for mixture of standard drugs with clear baseline was obtained (Fig. 3).

The validation parameters were studied for proposed HPTLC method and summary of validation parameters is shown in Table 1.

Table 1. Validation parameters of the method.

\begin{tabular}{|l|c|c|}
\hline Parameters & ROSI & GLIM \\
\hline Linearity range (ng/spot) & 100 to $1500 \mathrm{ng} /$ spot & 100 to $1500 \mathrm{ng} / \mathrm{spot}$ \\
\hline Precision (CV) & $0.4659 \%$ & $0.4876 \%$ \\
\hline$\%$ Recovery & $99.55 \pm 0.1868$ & $99.63 \pm 0.2138$ \\
\hline LOD (ng/spot) & 35 & 90 \\
\hline LOQ (ng/spot) & 30 & 85 \\
\hline Ruggedness & & \\
\hline Intraday (n=3) & 99.94 & 99.64 \\
\hline Interday $(\mathrm{n}=3)$ & 99.78 & 99.54 \\
\hline Analysts $(\mathrm{n}=3)$ & 99.66 & 99.82 \\
\hline
\end{tabular}

LOD: Limit of Detection, LOQ: Limit of Quantification.

Linearity

Linear relationships were observed by plotting the concentration of each analyte versus peak area. ROSI and GLIM showed linear response in the concentration range of 100-1500 ng/spot. The standard calibration graph and data for regression analysis are shown in Fig. 6, Fig. 7 and Table 2, respectively.

Table 2. Regression analysis data of the method.

\begin{tabular}{|l|c|c|}
\hline Parameters & ROSI & GLIM \\
\hline Linear Range (ng/spot) & $100-1500 \mathrm{ng} / \mathrm{spot}$ & $100-1500 \mathrm{ng} / \mathrm{spot}$ \\
\hline Slope & 0.1887 & 0.1469 \\
\hline Intercept & 16.218 & 13.407 \\
\hline Regression Co-efficient $\mathrm{R}^{2}$ & 0.9989 & 0.9996 \\
\hline
\end{tabular}

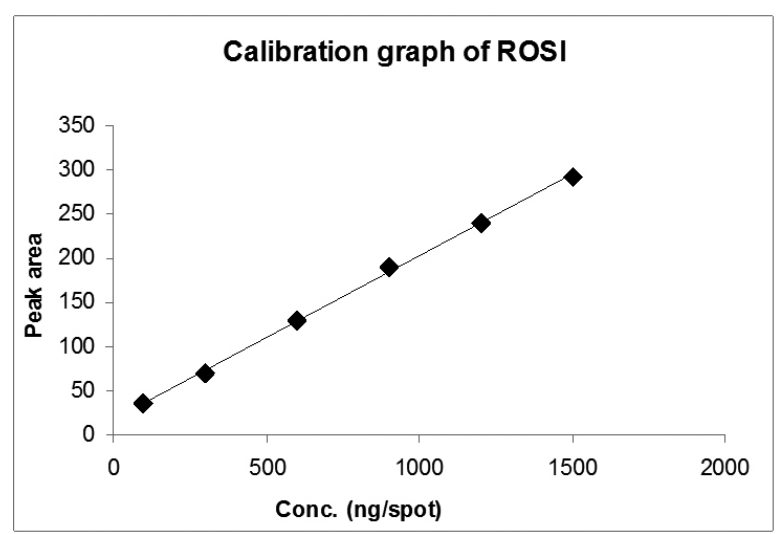

Fig. 6. Calibration graph for ROSI.

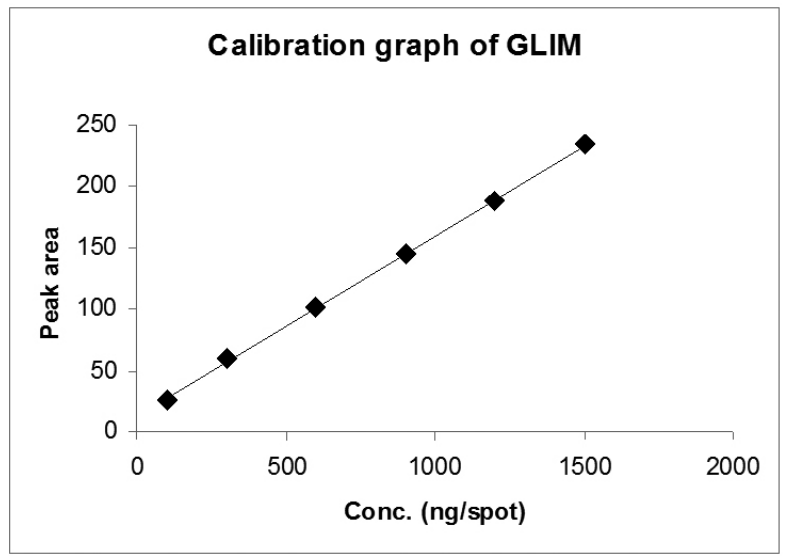

Fig. 7. Calibration graph for GLIM.

Precision

The results of the precision experiments are shown in Table 2. The developed method was found to be precise as the $\%$ RSD values for repeatability precision studies was $<2 \%$, as recommended by ICH guidelines.

$L O D$ and $L O Q$

The LOD and LOQ were found to be $35 \mathrm{ng} / \mathrm{spot}$ and $90 \mathrm{ng} / \mathrm{spot}$ for ROSI, $30 \mathrm{ng} / \mathrm{spot}$ and $85 \mathrm{ng} / \mathrm{spot}$ for GLIM, respectively.

Ruggedness

The standard deviation was calculated for each parameter and the $\%$ RSD were found to be less than $2 \%$. The low values of the $\%$ RSD, as shown in Table 2 indicated the ruggedness of the method.

Specificity

The peak purity of ROSI and GLIM was assessed by comparing their respective standard and sample chromatogram.

Accuracy

Accuracy was investigated by means of recovery studies using the proposed method. The mean recoveries $(\mathrm{n}=9) 99.55 \%$ and $99.63 \%$ obtained for ROSI and GLIM, respectively which demonstrate an adequate accuracy (Table 3).

\section{Analysis of formulation}

The results of analysis of pharmaceutical dosage form by the proposed method (Table 4), expressed as percentage of label claim were in good agreement with the label claims thereby suggesting that there is no interference from any of the excipients which are normally present in tablets. 
Table 3. Results of recovery studies.

\begin{tabular}{|c|c|c|c|c|c|c|}
\hline \multirow{2}{*}{ Drug } & Level (\%) & Amount taken & Amount added & $\begin{array}{c}\text { Total amount } \\
\text { found* }\end{array}$ & $\begin{array}{c}\text { Recovery* (\% } \pm \\
\text { SD) }\end{array}$ & $\begin{array}{c}\text { Average recovery } \\
\text { (\% } \pm \text { S.D.) }\end{array}$ \\
\hline \multirow{3}{*}{ ROSI } & 80 & 20 & 16 & 15.93 & 99.58 & \multirow{2}{*}{$99.55 \pm$} \\
\cline { 2 - 6 } & 100 & 20 & 20 & 19.94 & 99.72 & \multirow{2}{*}{0.1868} \\
\cline { 2 - 6 } & 120 & 20 & 24 & 23.84 & 99.35 & \multirow{2}{*}{$99.63 \pm$} \\
\cline { 2 - 6 } GLIM & 80 & 10 & 8 & 7.984 & 99.80 & \multirow{2}{*}{0.2138} \\
\cline { 2 - 6 } & 100 & 10 & 10 & 9.94 & 99.39 & 99.70 \\
\hline
\end{tabular}

*Average of three determinations, SD: Standard deviation.

Table 4. Analysis of formulation using the HPTLC method.

\begin{tabular}{|c|c|c|c|c|}
\hline Drug & $\begin{array}{c}\text { Amount } \\
\text { Labelled } \\
\text { (mg/tablet) }\end{array}$ & $\begin{array}{c}\text { Amount } \\
\text { Estimated* }\end{array}$ & $\begin{array}{c}\text { \% Label* } \\
\text { claim }\end{array}$ & CV \\
\hline ROSI & 2 & 1.9926 & 99.63 & 0.4659 \\
\hline GLIM & 1 & 0.9976 & 99.76 & 0.4876 \\
\hline
\end{tabular}

*Average of six determinations, CV: Coefficient of variance.

\section{CONCLUSION}

The proposed HPTLC method is precise, specific and accurate. Statistical analysis proves that the method is suitable for the simultaneous analysis of ROSI and GLIM in pharmaceutical formulation without any interference from the excipients. It was concluded that the developed method offered several advantages such as rapid, cost effective, simple mobile phase and sample preparation steps and improved sensitivity made it specific, reliable and easily reproducible in any quality control analysis providing all the parameters are followed accurately for its intended use.

\section{ACKNOWLEDGEMENTS}

Authors are thankful to Panacea Biotec Ltd., Malpur, Solan (H.P.), India and Medley Pharmaceuticals Ltd., Bari Brahmana, Jammu, India for providing the gift samples of drugs ROSI and GLIM, respectively. The authors are also thankful to Mr. B. K. Shrikhande, General Manager and Mr. S. S. Dhurde, Baidyanath Life Sciences Pvt. Ltd. Nagpur for helping to carry out the research work and Dr. K. P. Bhusari, Principal, Sharad Pawar College of Pharmacy, Nagpur for providing chemicals and laboratory facilities.

\section{REFERENCES}

1. H. P. Rang, M. M. Dale, J. M. Ritter, P. K. Moore. Pharmacology, 5th Edn. Edinburgh:Churchill Livingstone, 2003; pp. 310.

2. Indian Pharmacopoeia. Government of India Ministry of Health and Family Welfare, Indian Pharmacopoeia Commission, Ghaziabad, 2007; pp. 1674.

3. The Merck Index, In: An Encyclopedia of Chemicals, Drugs and Biologicals, S. Budavari eds., 13th Edn., Whitehouse Station, NJ, Merck Research Lab, 2001; pp. 1484.

4. B. Jamali, G. C. Theill, L. L. Sorensen, J. Chromatogr. A., 1049, 183, (2004).

5. J. He, Y. F. Hu, L. F. Duan, Z. R. Tan, L. S. Wang, D. Wang, W. Zhang, Z. Li, J. Liu, J. H. Tu, Y. M. Yao, H. H. Zhou, J. Pharm. Biomed. Anal., 43, 580, (2007).

6. T. Radhakrishna, J. Satyanarayana, A. Satyanarayana, J. Pharm. Biomed. Anal., 29, 873, (2002).

7. B. L. Kolte, B. B. Raut, A. A. Deo, M. A. Bagool, D. B. Shinde, $J$. Chromatogr. B., 788, 37, (2003).

8. P. Gomes, J. Sippel, A. Jablonski, M. Steppe, J. Pharm. Biomed. Anal., 36, 909, (2004).

9. C. Chau, M. Lee, F. Cheng, D. Yang, J. Chromatogr. A., 1097, 74, (2005)

10. A. Gumieniczek, A. Berecka, H. Hopkala, T. Mroczek, J. Liq. Chromatogr. Relat. Technol., 26(19), 3307, (2003).
11. The Merck Index, In: An Encyclopedia of Chemicals, Drugs and Biologicals, S. Budavari eds., 13th Edn., Whitehouse Station, NJ, Merck Research Lab, 2001; pp. 790.

12. S. Altinoz, D. Tekeli, J. Pharm. Biomed. Anal., 24, 507, (2001).

13. P. Kovarikova, J. Klimes, J. Dohnal, L. Tisovska, J. Pharm. Biomed. Anal., 36, 205, (2004).

14. Salem II, J. Idress, J. I. Tamini, J. Chromatogr. B., 799, 103, (2004).

15. R. T. Menon, S. Inamdar, M. Mote, A. Menezes, J. Planar Chromatogr., 17, 154, (2004).

16. S. R. Dhaneshwar, J. V. Salunkhe, V. K. Bhusari, J. Anal. Bioanal. Techniques., 1(3), 1, (2010).

17. International Conference on Harmonization Q2B, Validation of Analytical Procedures: Methodology, Geneva, 1996. 